\title{
La palabra militante en la generación del cuarenta y cincuenta: Hacia una po/ética de la escritura literaria
}

\begin{abstract}
Recibido: Marzo 2012 • Aceptado: Mayo 2012
"El joven se acomodó los anteojos con el índice. Luego explicó con lentitud, pensando cada palabra, la génesis del conflicto; pintó con unos brochazos dramáticos la vida de las peonadas: dio cifras de las fabulosas utilidades de la Compañía, y terminó exponiendo las reivindicaciones de los peones que sólo pudieron desembocar en el actual conflicto debido a la soberbia terquedad de la United Fruit Co." (Gutiérrez, 1976: 62. Fragmento extraído de la novela Puerto Limón de Joaquín Gutiérrez Mangel, 1950)
\end{abstract}

\section{RESUMEN}

La narrativa social-realista, inscrita en la década del cuarenta y cincuenta, elabora una concepción ética y estética del discurso literario cuyos procesos de producción y recepción merecen un particular enfoque teórico por parte de la crítica y los estudios literarios costarricenses. Tomando como referencia la figura retórica de Manuel Mora Valverde y su implicación ideológica con los autores más representativos de esta generación, todos ellos militantes del Partido Comunista costarricense, nuestra propuesta de estudio pretende descentralizar el carácter instrumental e ingenuamente expresivo con que generalmente se estudian las relaciones entre la militancia política y el hacer estético de esta generación con el fin de acercarnos, desde un enfoque semiótico y sociodiscursivo, al carácter dialéctico que subyace en la praxis ética y estética de esta narrativa y su concepción de escritura.

Palabras clave: palabra militante, Manuel Mora Valverde, generación del cuarenta-cincuenta, literatura costarricense, política y literatura.

* Máster en Filología Hispánica, Consejo Superior de Investigaciones Científicas (Madrid, España). Licenciado en Filología Española, Universidad de Costa Rica. Docente de la Cátedra de Lengua y Literatura, Universidad Estatal a Distancia, y profesor de la Cátedra de Comunicación y Lenguaje, Escuela de Estudios Generales, Universidad de Costa Rica. E-mail: mijailmondol@hotmail.com 


\begin{abstract}
The social-realistic narrative, inscribed in the 1940's and 1950's, elaborates an ethical and aesthetic conception of the literary discourse, whose production and reception processes deserve a particular theoretical approach from the critique and the Costa Rican literary studies. Departing from the rhetorical figure of Manuel Mora Valverde and his ideological implications with the most representative authors of this generation, all of them militant activists of the Costa Rican Communist Party, our purpose is to decentralize the instrumental and naively expressive temper in which the relationship between the political militancy and the aesthetic practice of this generation are usually studied. Our aim is to get us closer, from a semiotic and socio-discursive approach, to the dialectic character that underlies in the ethical and aesthetic praxis of this narrative and its writing conception.
\end{abstract}

Key words: militant word, Manuel Mora Valverde, 1940's and 1950's generation, Costa Rican literature, politics and literature.

\section{Introducción}

Desde el ámbito de los estudios literarios, la principal referencia de lectura que establece la crítica al estudiar la novelística social del cuarenta-cincuenta consiste en relacionar la militancia política de los escritores de esta generación con el Partido Comunista Costarricense, fundado en 1931 y dirigido por Manuel Mora Valverde.

De acuerdo con esta perspectiva, las aproximaciones críticas acerca de la narrativa social-realista, representada por los escritores Carmen Lyra, Carlos Luis Fallas, Adolfo Herrera García, Fabián Dobles y Joaquín Gutiérrez, tienden a restringir a la literatura bajo una concepción realista y testimonial, legitimando así una función instrumental del lenguaje y de la práctica estética. ${ }^{1}$ En palabras de Álvaro Quesada:
"En todos estos textos priva una concepción de la literatura como literatura comprometida con las luchas revolucionarias por transformar la realidad social y política. El escritor se concibe también como revolucionario o coadyuvante en un proceso de concienciación y transformación de la realidad social, que sus textos deben contribuir a aclarar, acelerar y estimular. [...] Como toda literatura realista estos textos asumen la función de ofrecer el reflejo de una realidad objetiva [...]" (Quesada, 2010: 15)

1. $\mathrm{Al}$ respecto de las convenciones ideológicas desde las cuales la crítica literaria ha estudiado la producción discursiva de esta generación, véase el estudio de Manuel Picado Gómez, Literaturalideologíalcrítica (1983). En este ensayo, Picado, mediante el concepto del verosímil crítico, analiza los criterios metodológicos y teóricos desde los cuales la crítica literaria construye su percepción acerca de la generación literaria del cuarenta y cincuenta. 
Si bien es cierto, la vinculación política que establecen algunos de estos escritores con el Partido Comunista supone el criterio historiográfico más inmediato para comprender las implicaciones ideológicas de la producción literaria del cuarenta, esta forma de abordaje resulta insuficiente para comprender la unidad poética y fundamentalmente dialéctica que se establece entre la praxis política y la escritura literaria desarrollada por esta generación.

Con base en la premisa anterior, la hipótesis central de estudio radica en afirmar que la relación entre militancia política y escritura literaria que se formula en este periodo de la literatura costarricense responde a una concepción del lenguaje y de su horizonte ético-ideológico.

\section{La palabra militante: hacia una po/ética de la recepción literaria}

Asumiendo el principio de que toda formación social elabora sus propias prácticas y convenciones de lenguaje, la producción discursiva de la generación del cuarenta se articula bajo un mismo horizonte de expectativas cuya característica principal radica en conceptualizar el lenguaje desde una dimensión ética e histórica. En vista de que esta conceptualización pasa necesariamente por el consenso y la legitimación social, la palabra militante desarrollada en el marco sociopolítico de esta generación se convierte en el paradigma dóxico que rige los procesos de enunciación y recepción del discurso. Así, pues, la palabra militante, en tanto ideologema discursivo de la generación del cuarenta, constituye el principal dispositivo semiótico a partir del cual la literatura y la praxis política convergen en un mismo nivel de enunciación y de significación social.

Por otra parte, a diferencia de la concepción monológica y determinista desde la cual los estudios críticos e historiográficos tienden a dimensionar las relaciones expresivas entre la literatura y la política, es importante subrayar que la llamada palabra militante se enmarca dentro de un proceso comunicativo de carácter dialógico. Esto quiere decir que no debe relacionarse con una palabra dicha o acontecida en el enunciado, sino que más bien constituye una palabra en espera de su acontecimiento, lo cual significa que esta actúa siempre en función de una respuesta, valga decir de un tercero o un sujeto histórico que la ponga en acto. Por esta razón, la palabra militante, tal y como la concebimos, funciona principalmente desde un horizonte ético de lectura y comprensión. Ello quiere decir que la palabra militante no 
expresa un sentido o contenido político, sino que siempre está en espera de una significación política que la capture y la comprenda.

\section{Manuel Mora Valderde en la representación estética de la palabra militante}

Con el fin de demostrar el funcionamiento ideológico de la palabra militante en el discurso estético, esta puede verse semióticamente formulada en una de las representaciones pictóricas más conocidas de Manuel Mora Valverde. Tal es el caso de un boceto elaborado por el pintor Fernando Carballo en el cual se retrata la figura del dirigente Mora y cuyo análisis nos permitirá comprender la forma en que la palabra militante se ve refractada en el discurso estético.

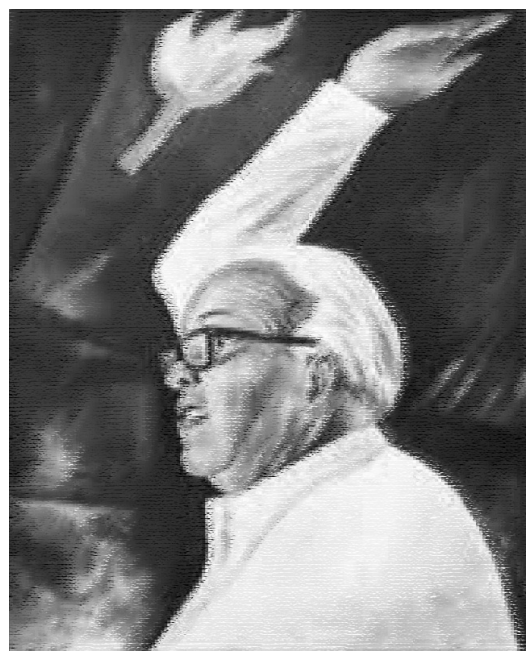

Como se puede apreciar en la imagen anterior, la representación pictórica se encuentra organizada a partir de la vinculación entre la figura del dirigente comunista y el ejercicio retórico de la oralidad. Para llevar a cabo esta figuración, la imagen dispone de una serie de signos o enunciados semióticos (la antorcha, la mirada fija, los lentes y el brazo enérgicamente levantado) los cuales pretenden representar la actitud oral y militante de Manuel Mora Valverde.

Así, pues, resulta importante destacar, entre otras funciones enunciativas, la mediación ideológica que ocupa la antorcha figurada en el plano izquierdo del retrato y la cual guarda una relación simbólica con el brazo levantado enérgicamente por Manuel Mora. Si bien es cierto, esta mediación simbólica constituye una estrategia de representación heredada del realismo socialista, esta no deja de implicar una valiosa significación en lo que en este estudio hemos denominado la palabra militante. La relación metafórica fuego-palabra, emblemáticamente representada por el fuego de la antorcha y figurada a la vez en el brazo y la mano del dirigente, sintetiza, en gran medida, el núcleo básico a partir del cual el signo pictórico adquiere una significación política.

Tomando como punto de partida que la palabra militante no 
actúa en el enunciado, sino en el proceso de enunciación y recepción del discurso, es claro deducir que los signos desde los cuales se articula este texto pictórico no pretenden comunicar un contenido político respecto a su imagen, sino más bien se encuentran apuntando al gesto político desde el cual se enuncia y se desdibuja la oralidad del dirigente Manuel Mora. He aquí precisamente la naturaleza dialéctica desde el cual se articula la dimensión estética y ética de la palabra militante: su deseo de imponer un más allá de la representación y del lenguaje. Por este motivo, la unidad ética y estética de la palabra obedece en realidad a un espacio de contradicción donde el lenguaje apunta siempre hacia algo más que su significante con el fin de introducirse en el acto ético de la interpretación. Pero, ¿cómo asociar este mecanismo con la escritura literaria del cuarenta-cincuenta?

\section{Escrituras políticas/escrituras literarias: la palabra militante en la generación del cuarenta}

En el apartado anterior, aludíamos a la forma en que la palabra militante, entendida como un horizonte valorativo de recepción y producción del discurso de la década del cuarenta, adquiere una significación política en una de las representaciones pictóricas más destacadas del dirigente Manuel Mora Valverde. En el siguiente apartado, resta acercarnos al tipo de estrategias semióticas y discursivas que utiliza la palabra militante en el discurso escrito o narrativo de esta generación. Para llevar a cabo esta perspectiva de análisis, resulta importante mencionar las siguientes premisas teóricas en torno a la práctica de escritura desde la cual se materializa el efecto estético o literario.

1. En primer lugar, resulta necesario ubicar la literatura en términos de producción y transformación del sentido. Esta perspectiva de análisis invita a conceptualizarla en términos de una praxis material de sentido, en la que el fenómeno literario dista de establecer una función estrictamente comunicativa y se enmarca dentro de un proceso, un trabajo específico de enunciación.

2. Ligado a la dimensión de praxis literaria anteriormente citada, resulta importante comprender la literatura como un campo contradictorio de mediaciones discursivas. Dado que la noción de praxis se encuentra intrínsecamente relacionada con los procesos de enunciación del discurso, la literatura actúa como un 
campo sociotextual donde se contra-dicen y se infiltran los discursos, las representaciones sociales y hasta las propias convenciones o valoraciones del lenguaje.

En el caso específico de la generación del cuarenta, la escritura literaria evidencia distintos mecanismos de centralización y descentralización de la palabra militante, lo cual, como señalábamos líneas atrás, define su naturaleza ambivalente y contradictoria. Este tipo de escritura se inscribe dentro de un determinado sistema valorativo e ideológico del discurso, al mismo tiempo que elabora sus propias estrategias textuales y referenciales para desligarse de una noción estética de lo literario.

Una primera particularidad en torno a la escritura literaria de esta generación subyace en los procesos de mediación semiótica que se establecen entre la escritura literaria y el referente sociotextual. Dado que la formación políticodiscursiva del cuarenta se encuentra atravesada por las convenciones estético-ideológicas de la palabra militante, es claro identificar, en algunas de las prácticas novelísticas de esta generación, la tendencia poética a establecer un acercamiento performativo entre la palabra y su referente. Como vimos hace un momento, cuando nos referíamos a la imagen figurativa de Manuel Mora Valverde, esta performatividad de la palabra, este gesto exhortativo de la oralidad, se encuentra atravesado en la praxis novelística de algunos de los autores de la década del cuarenta y cincuenta. Por este motivo, se vuelve necesario estudiar las estrategias textuales y discursivas que buscan neutralizar, naturalizar, las mediaciones y el espacio de conflicto que se desarrolla entre el ámbito estético-ficcional y el discurso social.

\section{Problemas estéticos en la palabra militante}

Cuando nos acercamos, desde un punto de vista formal, a la llamada narrativa social realista del cuarenta, el principal efecto estético que sobresale en las producciones narrativas de esta generación radica en el concepto de verosimilitud, ampliamente desarrollado por la teoría literaria.

En el ámbito de los estudios literarios costarricenses, uno de los primeros investigadores en señalar el carácter verosímil desde el cual trabaja la producción estética y crítica de la llamada generación del cuarenta y cincuenta es Manuel Picado Gómez, en su ensayo Literaturalideologíalcrítica (1983).

Siguiendo los postulados de Gérard Genette y Tzvetan Todorov, Picado sostiene que la función 
de la verosimilitud radica en crear un efecto de "naturalidad" entre el lenguaje estético (aunque también puede ser referido a cualquier otro tipo de discurso) y su referente extratextual:

"La función de la verosimilitud consiste en crear mecanismos que hagan creer que el discurso literario no está regido por las leyes propias del simbolismo, sino por las de su referencia y (dependencia) de lo real." (Picado, 1983: 31)

Líneas más abajo, Picado insiste en esclarecer el concepto de verosimilitud a partir de los propios señalamientos que realiza Todorov en torno a este concepto:

"Se hablará de verosimilitud de una obra en la medida en que esta trate de hacer creer que se conforma a lo real y no a sus propias leyes; dicho de otro modo, lo verosímil es la máscara con que se disfrazan las leyes del texto y que nosotros debemos tomar por una relación con la realidad." (Todorov, en Picado, 1983: 31) (La cursiva es mía.)

De este modo, el tratamiento metacrítico de Picado en torno a la verosimilitud nos permite comprender la estrategia discursiva utilizada por el discurso literario y crítico para condicionar los mecanismos de recepción que tuvo la llamada novelística social del cuarenta y cincuenta. Asimismo, el concepto de verosimilitud desarrollado por Picado explica la forma en que la crítica y la recepción literaria neutraliza la contradicción que se produce en esta producción narrativa, pero no nos permite comprender el carácter dialéctico y dinámico desde el cual se articula y se genera la escritura socialrealista propuesta por esta promoción de escritores. ¿En qué consiste, pues, el carácter dialéctico de esta narrativa?

\section{Tesis: el horizonte ético}

El primer punto por destacar en la producción discursiva e ideológica de la generación del cuarenta radica en su carácter ético. Esto quiere decir que el horizonte valorativo, histórico y representacional adquiere en esta generación una unidad de sentido y significación la cual converge en una determinada concepción del lenguaje $y$, por tanto, en un modo de recepción específico: la verosimilitud. Nótese, pues, que a diferencia de la centralidad que ocupa este último concepto para explicar el discurso literario de la generación del cuarenta y cincuenta, nuestra propuesta de análisis consiste en pensar la especificidad histórica e ideológica que tuvo esta generación como el principal núcleo de significación a partir del cual se produce y se manifiesta su particularidad estética y formal. 
Antítesis: discurso político versus convención literaria

Una vez que el horizonte ideológico y ético de esta generación se proyecta como una voz de/enunciativa de la realidad y la injusticia social, el campo literario y significante entra en una dinámica de contradicción en el cual comienzan a producirse ciertas tensiones entre las propiedades ficcionales, formales que rigen la convención estética (realismo literario) y las valoraciones político-ideológicas, inscritas en una determinada conciencia social e histórica. ${ }^{2}$

$\mathrm{Al}$ respecto de lo anterior, léase el siguiente comentario de Roland Barthes respecto de las tensiones entre la escritura comunista y la utilización de los modelos y concepciones literarias elaborados por la pequeña burguesía:

"Esta escritura pequeño burguesa fue retomada por los escritores comunistas, porque, momentáneamente, las normas artísticas del proletariado no pueden ser distintas de las de la pequeña burguesía. (...) Se comprende entonces la paradoja según la cual la escritura

2. La tensión producida entre el género literario y la ética autoral (en este caso representada por la conciencia política de la generación del cuarenta-cincuenta), constituye uno de los problemas estéticos menos discutidos en el estudio de esta generación. comunista multiplica los signos más burdos de la Literatura y lejos de romper con una forma, en definitiva típicamente burguesa-al menos en el pasado- sigue asumiendo sin reservar las preocupaciones formales del arte de escribir pequeño burgués." (Barthes, 2000: 72) (La cursiva es mía.)

Síntesis: la palabra militante

Finalmente, para comprender el carácter dialéctico que rige la narrativa social realista del cuarentacincuenta, nuestra propuesta de estudio tiende a considerar que las tensiones generadas entre la convención estética (realismo literario) y el horizonte ético-ideológico que se formula en la conciencia política del cuarenta-cincuenta, tienden a refractarse en una serie de recursos retóricos y procedimientos textuales que definen el estilo narrativo de esta generación. Precisamente a este estilo y recepción particular los denominamos la palabra militante de la narrativa social-realista del cuarenta y cincuenta.

\section{Análisis}

Con el fin de referirme a las estrategias discursivas que caracterizan el efecto estético-ideológico de esta producción narrativa, realizaré un breve análisis en torno a dos obras representativas de este 
periodo: Juan Varela (1939), de Adolfo Herrera García, y Mamita Yunai (1941), de Carlos Luis Fallas.

\section{Utilización del discurso no ficcional}

Desde el principio de la novela Juan Varela, podemos notar la enunciación de una dedicatoria en la que el autor ofrece su obra literaria al hijo primogénito de Juan Varela y Ana Madrigal. Lo más interesante de esta referencia radica en que estos dos personajes figuran en la novela como los dos personajes protagónicos y ficcionales del texto. De este modo, independientemente de que el lector asuma la existencia verdadera de estas entidades, resulta interesante analizar este fragmento inicial de la novela como una estrategia discursiva que apunta hacia algo más que la referencia intratextual. La dedicatoria, al igual que la imagen anteriormente comentada de Manuel Mora, establece un pacto de lectura con el fin de ser significada desde un punto de vista testimonial e histórico.

Esta misma estrategia semiótica la podemos comprobar en la utilización del discurso jurídico presente a lo largo de la novela. Al respecto de lo anterior, véase a continuación la siguiente cita textual en la cual se ejemplifica la utilización del documento jurídico como parte de la estructura estética de la novela:

"En el Boletín Judicial No. 26 del año XLIII estaba publicado: Juan Varela Conejo, mayor, soltero, jornalero, vecino de Santa Bárbara de Heredia, denuncia un lote de terreno baldio, constante de veinte hectáreas, situado en las bajuras de la Barranca, distrito segundo del cantón segundo de la provincia de Alajuela. [...] Con treinta días de término cito a los que tengan derechos que alegar a este denuncio que los hagan valer ante esta autoridad. Juzgado Primero de lo Contencioso Administrativo. San José, 29 de enero de 19..." (Herrera, 1993: 1)

En el caso de Fallas y su novela Mamita Yunai, las mediaciones entre el discurso literario y el discurso sociorreferencial se encuentran condensadas en el registro biográfico que realiza previamente el autor. Así, por ejemplo, en la edición de 1957, el texto de Mamita Yunai se encuentra precedido por una autobiografía de Carlos Luis Fallas en la cual se enfatiza en sus vivencias como trabajador bananero y militante político. De este modo, se vuelve explícito que el valor testimonial, del que sin duda vivió Carlos Luis Fallas durante la década del treinta, es partícipe de las estrategias textuales y de los contratos de lectura que tienden a pactar con el lector un código de verosimilitud y legitimidad histórica. En este 
mismo sentido, también resulta interesante destacar la última parte de este texto, en el cual se anexa el discurso emitido por Carlos Luis Fallas en la Huelga Bananera del Pacífico. Al igual que el documento jurídico presente en la novela Juan Varela, de Adolfo Herrera García, nótese a raíz del siguiente extracto, las estrategias semióticas y textuales que utiliza la palabra militante para mediar entre el discurso ficcional y el discurso político emitido por Fallas.

“Compañeros:

Vengo gustoso a intervenir en esta asamblea de solidaridad con los huelguistas de Puerto González Viquez y lo hago en mi condición de costarricense, de extrabajador de la United Fruit Company, de exdirigente de la Federación de Trabajadores Bananeros del Atlántico y luego de la Federación de Trabajadores Bananeros del Pacífico, y también en mi condición de dirigente de la gran huelga bananera de 1934. [...] Yo llegué muy muchacho a la zona bananera. Algunas de mis experiencias de ese tiempo se conocen a través de mi libro 'Mamita Yunai', alli está reflejada en parte la dura y humillante vida que entonces soportábamos en la zona bananera del Atlántico [...] iA la calle, compañeros, el próximo sábado, desde las nueve de la mañana! ;Adelante con esta patriótica campaña de solidaridad con los abnegados huelguistas del Pacífico!" (Fallas, 1986: 183-203)

Presencia de la voz autoral en el discurso narrativo del realismo social

Finalmente, se debe destacar que la voz narrativa-autoral desarrollada en las producciones narrativas de esta generación introduce una serie de criterios $\mathrm{u}$ opiniones de índole histórica, política y filosófica. Esta característica ilustra muy bien la intención didáctica e ideológica que se proponía cumplir esta generación en relación con sus destinatarios (los lectores) así como el horizonte ético desde el cual toma posición política el discurso literario.

A manera de ejemplo, nótese mediante las siguientes citas textuales, la participación activa que cumple la voz narrativa y autoral en la descripción del espacio, la visión de mundo de los personajes y las relaciones sociales desarrolladas en el mundo ficcional de las novelas Vida y dolores de Juan Varela (1939), de Adolfo Herrera García; Mamita Yunai (1941), de Carlos Luis Fallas; y El sitio de las abras (1950), de Fabián Dobles. 
"Los alambres de las cercas son los hilos telegráficos que transmiten a los hombres el mensaje de las supremas injusticias." (Herrera, 1994: 47)

"Esos indios que casi lloraban implorando un pedazo de carne o un jarro de guaro, ¿eran los descendientes de aquellos belicosos talamancas? ¿No fueron sus antepasados lo que hicieron famoso, con su bravura, el nombre de su región en los tiempos de la Colonia? ¿No fue esta raza, altiva, otrora, la que mantuvo en jaque el audaz y fiero conquistador hispano?" (Fallas, 1986: 69)

“¡Era tan fácil para un poderoso hacer imposible la vida de unos cuantos finqueros cercados del todo por sus tierras!" (Dobles, 1993: 216)
Vida y dolores de Juan Varela (1939), de Adolfo Herrera García

Temática agraria.

Mamita Yunai (1941), Carlos Luis Fallas Temáticas:

Condiciones de vida y explotación obrera por parte de la United Fruit Company.

Marginalidad indígena.

El sitio de las abras (1950), de Fabián Dobles Tema agrario, la defensa de la propiedad de la tierra y la organización colectiva.
Como podemos observar a la luz de estos dos breves ejemplos, las estrategias textuales que busca establecer la narrativa social-realista del cuarenta permite comprender las formas en que la palabra militante se refracta y adquiere significación política en el discurso estético.

\section{Conclusiones}

Si bien es cierto, las condiciones de enunciación de este discurso literario se encuentran sujetas al contexto político-ideológico en que se vio inmersa la mayoría de los escritores de esta generación, desde el punto de vista de la recepción y producción del discurso, su praxis de escritura se inscribe dentro de un mismo horizonte de expectativas y concepción del lenguaje.

Con base en lo anterior, la relación entre militancia política y escritura literaria formulada en este periodo de la literatura costarricense, no solamente evidencia un modelo discursivo circunscrito a las luchas sociales gestadas por el Partido Comunista, sino que también revela un posicionamiento político de la literatura, valga decir una polética del decir y la recepción literaria.

Así, pues, más allá de una estrategia expresiva del lenguaje, la toma política de la palabra por parte de esta generación constituye, como bien señala Roland Barthes, una pulsión revolucionaria de toda escritura: "la función de imponer 
un más allá del lenguaje que es a la vez la Historia y la posición que se toma frente a ella" (Barthes, 2000: 11). Precisamente de aquí, en este acto ético que cumple la escritura literaria con su devenir histórico y social, se deriva el concepto de la palabra militante. No por casualidad, si Manuel Mora hacía política en su oralidad, los escritores de la generación del cuarenta hacían política en su literatura.

\section{Bibliografía}

Barthes, Roland (2000). El grado cero de la escritura. México: Editorial Siglo Veintiuno.
Dobles, Fabián (1993). Obras Completas. Tomo I. San José: Editorial Costa Rica.

Fallas, Carlos Luis (1986). Mamita Yunai. San José: Editorial Costa Rica.

Gutiérrez Mangel, Joaquín (1976). Puerto Limón. San José: Editorial Costa Rica.

Herrera García, Adolfo (1993). Juan Varela. San José: Editorial Costa Rica.

Picado Gómez, Manuel (1983). Literatural ideologíalcrítica. Notas para un estudio de la literatura costarricense. San José: Editorial Costa Rica.

Quesada Soto, Álvaro (2010). Rutas de subversión. La novela de los años cuarenta. San José: Editorial Universidad de Costa Rica. Colección Identidad Cultural. 